\title{
FAM168A participates in the development of chronic myeloid leukemia via BCR-ABL1/ AKT1/NFkB pathway
}

\author{
Xiaorong Liu', Huirong Mai ${ }^{2}$, Hanfang Jiang ${ }^{1}$, Zhihao Xing ${ }^{1}$, Dong Peng', Yuan Kong ${ }^{1}$, Chunqing Zhu' \\ and Yunsheng Chen ${ }^{1 *}$ (D)
}

\begin{abstract}
Background: Although the prognosis of chronic myeloid leukemia (CML) has dramatically improved, the pathogenesis of CML remains elusive. Studies have shown that sustained phosphorylation of AKT1 plays a crucial role in the proliferation of CML cells. Evidence indicates that in tongue cancer cells, FAM168A, also known as tongue cancer resistance-associated protein (TCRP1), can directly bind to AKT1 and regulate AKT1/NFKB signaling pathways. This study aimed to investigate the role of FAM168A in regulation of AKT1/NFKB signaling pathway and cell cycle in CML.

Methods: FAM168A interference was performed, and the expression and phosphorylation of FAM168A downstream proteins were measured in K562 CML cell line. The possible roles of FAM168A in the proliferation of CML cells were investigated using in vitro cell culture, in vivo animal models and clinical specimens.

Results: We found that the expression of FAM168A significantly increased in the peripheral blood mononuclear cells of CML patients, compared with normal healthy controls. FAM168A interference did not change AKT1 protein expression, but significantly decreased AKT1 phosphorylation, significantly increased IKB-a protein level, and significantly reduced nuclear NFkB protein level. Moreover, there was a significant increase of G2/M phase cells and Cyclin B1 level. Immunoprecipitation results showed that FAM168A interacts with breakpoint cluster region (BCR) -Abelson murine leukemia (ABL1) fusion protein and AKT1, respectively. Animal experiments confirmed that FAM168A interference prolonged the survival and reduced the tumor formation in mice inoculated with $\mathrm{K} 562$ cells. The results of clinical specimens showed that FAM168A expression and AKT1 phosphorylation were significantly elevated in CML patients.

Conclusion: This study demonstrates that FAM168A may act as a linker protein that binds to BCR-ABL1 and AKT1, which further mediates the downstream signaling pathways in CML. Our findings demonstrate that FAM168A may be involved in the regulation of AKT1/NFKB signaling pathway and cell cycle in CML.
\end{abstract}

Keywords: Chronic myeloid leukemia, FAM168A, Cell proliferation, AKT1, BCR-ABL1

\section{Background}

Chronic myelogenous leukemia (CML) is a malignant tumor formed by clonal proliferation of bone marrow hematopoietic stem cells. Due to the proliferation and infiltration of cloned leukemia cells in bone marrow and other hematopoietic tissues, normal hematopoietic function is inhibited. The clinical manifestations include anemia, hemorrhage, weight loss, upper abdominal

\footnotetext{
* Correspondence: chenyunshenglw@163.com

${ }^{1}$ Clinical laboratory, Shenzhen Children's Hospital, No. 7019, Yitian Road,

Shenzhen, Guangdong 518038, People's Republic of China

Full list of author information is available at the end of the article
}

discomfort, and splenomegaly. CML can occur in people of any age, with an annual global incidence of (1.6-2)/ 100,000 [1]. The incidence of CML increases with age. Although tyrosine kinase inhibitors have made a great breakthrough in the treatment of CML, little is known about the pathogenesis of CML.

More than 95\% of CML patients have characteristic Philadelphia chromosome $(\mathrm{Ph})$, which is produced by the translocation of chromosome 9 and $22 \mathrm{t}(9 ; 22)$ (q34; q11) $[2,3]$. Studies have shown that the Philadelphia chromosome produces a fusion gene, which in turn encodes the BCR-ABL1 fusion protein. This enzyme has

(c) The Author(s). 2019 Open Access This article is distributed under the terms of the Creative Commons Attribution 4.0 International License (http://creativecommons.org/licenses/by/4.0/), which permits unrestricted use, distribution, and reproduction in any medium, provided you give appropriate credit to the original author(s) and the source, provide a link to the Creative Commons license, and indicate if changes were made. The Creative Commons Public Domain Dedication waiver (http://creativecommons.org/publicdomain/zero/1.0/) applies to the data made available in this article, unless otherwise stated. 
a sustained tyrosine kinase activity and it can promote phosphorylation of downstream signaling proteins such as AKT1, ERK, and STAT1. It can also increase the expression of oncogene c-Myc and apoptosis suppressor gene Bcl-2, and promote cell proliferation and survival [4-6]. However, it is still unclear how BCR-ABL1 protein promotes the sustained phosphorylation of AKT1 protein.

FAM168A, also known as tongue cancer resistanceassociated protein 1 (TCRP1) was discovered in studies of multidrug resistance of tongue cancer cells. FAM168A gene is located on chromosome ll, and its protein consists of 235 amino acids with a molecular weight of $25 \mathrm{kDa}$ [7]. Studies show that FAM168A mediates tumor cell cisplatin resistance and radiotherapy tolerance [7-11]. In one study researchers used human toxicology and drug resistance microarray (OHS-401) in combination with immunoprecipitation to detect the gene expression profiles in FAM168A-overexpression and FAM168A-knockout tongue cancer cell lines. They found that FAM168A directly binds to AKT1 [9]. Moreover, a decrease in AKT1 and NFkB expression was observed in FAM168A-deletion cells. These results indicate that FAM168A may promote tumor cell proliferation and reduce apoptosis via $\mathrm{AKT} 1 / \mathrm{NFKB}$ signaling pathway $[9,11]$. Here we investigated the impact of FAM168A interference on FAM168A expression and AKT1 phosphorylation in K562 CML cell line, in vivo animal model and clinical specimens. Our study provides theoretical and clinical basis for the development of new CML therapeutic targets.

\section{Methods}

\section{Materials}

RIPA lysis and extraction buffer was purchased from Beyotime Biotechnology Co., Ltd. (Jiangsu, China). PhosSTOP Phosphatase Inhibitor Cocktail Tablets were purchased from Roche (Shanghai, China). Nuclear protein extraction kit was purchased from Active Motif Co., Ltd. (Shanghai, China). Protease inhibitor cocktail set III was purchased from EMD Biosciences (Germany). FAM168A antibody [FAM168A (E-13)] was purchased from Santa Cruz (U.S.A.). AKT1 antibody, p-AKT1 antibody, $\beta$-actin antibody, HRP-conjugated secondary antibodies, goat anti-rabbit IgG and horse anti-mouse IgG were purchased from Cell Signaling (U.S.A.). Fetal bovine serum, IMEM media, and trypsin were purchased from Invitrogen (U.S.A.). BCA protein assay kit was purchased from Pierce Corporation (U.S.A.). SDS, Tris-Cl, EDTA, and acrylamide were purchased from Sigma (U.S.A.).

Human chronic myeloid leukemia cell line K562 was purchased from China Center for Type Culture Collection. K562 cells were cultured in IMEM media containing $10 \%$ fetal bovine serum at $37^{\circ} \mathrm{C}$ with $5 \% \mathrm{CO}_{2}$. Cells in logarithmic growth phase were selected.
Twenty-one male NOD/SCID mice, 5-6 weeks of age, weighing $25-30$ g, were purchased from Nanjing UniversityNanjing Institute of Biomedical Research (Qualification No.: 32002100001171), and were housed in specificpathogen-free (SPF) laminar air flow rooms [equipment qualification certificate: SYXK (Guangdong) 2012-0119] at Shenzhen Institute of Advanced Technology. Animals had free access to food and water. The study was approved by the Laboratory Animal Ethics Committee of the Shenzhen Advanced Institute of the Chinese Academy of Sciences.

Three patients, 2 males (6-10 years old) and 1 female (6-10 years old), with CML hospitalized in the Department of Hematology and Oncology at our hospital from March 2018 to May 2018 were included. These patients were newly diagnosed with CML. The clinical features of patients are shown in the Additional file 1: Table S1. Peripheral blood $(2 \mathrm{~mL})$ were collected from these patients before treatment. During the same time period, 3 healthy children underwent annual physical examination were selected, including 2 males and 1 female, 6-9 years of age, and $2 \mathrm{~mL}$ of peripheral blood were collected. The study was approved by the hospital's ethics committee. Informed consents were signed by the parents of every child before the blood collection.

\section{Methods \\ Specimens collection}

Inclusion criteria for CML patients were as follows: patients who had typical elevated white blood cell counts and abnormalities in classification, splenomegaly with $\mathrm{Ph}$ chromosomes or their variant karyotypes, and BCRABL1 fusion gene positivity according to the clinical diagnosis. Inclusion criteria for healthy controls were as follows: healthy children who had no underlying diseases. $2 \mathrm{~mL}$ of peripheral blood was collected from the patients and the healthy controls using EDTAK2 anticoagulant tubes and stored at $4{ }^{\circ} \mathrm{C}$ until use.

\section{Isolation of peripheral blood mononuclear cells}

The whole blood was diluted with equal amount of D-Hank's solution or PBS. $2 \mathrm{~mL}$ of the diluted blood was added along the wall of the tube into $1 \mathrm{~mL}$ of lymphocyte isolation solution and centrifuged at $400 \mathrm{xg}$ for $20 \mathrm{~min}$ at $15{ }^{\circ} \mathrm{C}$. The white lymphocyte layer was collected using a capillary pipette, placed in another centrifuge tube and washed with PBS for 3 times to collect the cells.

\section{Cell culture}

K562 cells were cultured in IMEM media (Thermo Fisher Scientific, U.S.A.) containing 10\% fetal bovine serum (Thermo Fisher Scientific, U.S.A.), and incubated at $37^{\circ} \mathrm{C}$ with $5 \% \mathrm{CO}_{2}$. The cells in logarithmic growth phase were selected. 


\section{FAM168A siRNA interference}

The siRNA sequence for the FAM168A exon (5'- GCCU CAUGUCAUCCACCAU - 3') and the negative control siRNA sequence were designed and synthesized by Guangzhou Ruibo Biotechnology Co., Ltd. (Guandong, China). K562 cells were seeded into 6-well plates at a density of $3 \times 10^{5}$ per well. Next day, the siRNAs and Lipofectamine 2000 were dissolved in serum-free media, mixed, and incubated at room temperature for $20 \mathrm{~min}$. siRNAs/Lipofectamine 2000 mixtures were added to the cells, and cultured for $48 \mathrm{~h}$.

\section{RNA isolation and first strand CDNA synthesis}

$5 \times 10^{5}$ PBMCs and K562 cells were collected and homogenized in $1 \mathrm{~mL}$ Trizol. $0.2 \mathrm{~mL}$ chloroform was added, vortexed, and centrifuged at 2,000 x g for $15 \mathrm{~min}$ at $4{ }^{\circ} \mathrm{C}$. The upper aqueous phase was collected and $0.5 \mathrm{~mL}$ isopropanol was added. After high-speed centrifugation, the supernatant was discarded. The RNA pallet was washed with $75 \%$ ethanol and centrifuged to remove the supernatant. The pellet was dried and dissolved in DEPC-treated water. RNA concentration and quality were measured, and stored at $-70^{\circ} \mathrm{C}$. For reverse transcription, $2 \mathrm{U}$ DNase I was added to $1 \mu \mathrm{g}$ RNA and incubate at $37^{\circ} \mathrm{C}$ for $30 \mathrm{~min}$ to remove the genomic DNA. EDTA was added to stop the reaction. Oligo (dT) primers and reverse transcriptase were added to the RNA and incubate at $42^{\circ} \mathrm{C}$ for $60 \mathrm{~min}$. The reaction was stopped by heating at $70^{\circ} \mathrm{C}$ for $5 \mathrm{~min}$.

\section{Real-time quantitative $P C R$}

A total of $20 \mu \mathrm{L}$ of reaction system was used and 3 replicates were set for each sample. Real-time PCR program was as follows: $95^{\circ} \mathrm{C}$ for $10 \mathrm{~min} ; 95^{\circ} \mathrm{C}$ for $15 \mathrm{~s}, 60^{\circ} \mathrm{C}$ for 1 min, 40 cycles. The melting curve was plotted at $70^{\circ} \mathrm{C}$ to $95^{\circ} \mathrm{C}$. The experiment was repeated three times. $\beta$-Actin was used as an internal reference control. The gene expression was calculated by comparative $\mathrm{Ct}$ method $\left(2^{-\Delta \Delta \mathrm{Ct}}\right.$ method). The $\Delta \Delta \mathrm{Ct}$ was calculated as: $\Delta \Delta \mathrm{Ct}=[$ (target gene $\mathrm{Ct}$ - internal reference $\mathrm{Ct}$ ) treatment group - (target gene $\mathrm{Ct}$ - internal reference $\mathrm{Ct}$ ) control group]. Real-time PCR detection primers for FAM168A were: 5'-GAAC TCGTCTTC CTGTGGCA-3' (FAM168A-F) and 5'GGGGTGGAGCAGTGTTACTC-3' (FAM168A-R). Detection primers for $\beta$-Actin were: $5^{\prime}$-CTCACCATGGAT GATGATATCGC-3' ( $\beta$-Actin-F) and 5'-AGGAATCCT TCTGACCCATGC-3' ( $\beta$-Actin-R).

\section{Nuclear protein extraction}

K562 cells were cultured in $10-\mathrm{cm}$ cell culture dishes. When the cells reached $80 \%$ confluence, the media were removed, and the cells were washed with $5 \mathrm{~mL}$ of icecold PBS containing phosphatase inhibitor. After centrifugation, the supernatant was removed. Nuclear protein extraction kit was used to extract nuclear protein. In brief, the cells were gently resuspended in $500 \mu \mathrm{L} 1 \times$ hypotonic buffer, transferred to a $1.5 \mathrm{~mL}$ ice-cold centrifuge tube, and incubated on ice for $15 \mathrm{~min} .25 \mu \mathrm{L}$ detergent solution was added, vortexed for $10 \mathrm{~s}$, and centrifuged at $14,000 \times \mathrm{g}$ for $30 \mathrm{~s}$ at $4{ }^{\circ} \mathrm{C}$. The pellet was resuspended in $50 \mu \mathrm{L}$ complete lysis buffer, vortexed for $10 \mathrm{~s}$, incubated on ice for $30 \mathrm{~min}$, vortexed for $30 \mathrm{~s}$, and centrifuged at $14,000 \mathrm{x} \mathrm{g}$ for $10 \mathrm{~min}$ at $4{ }^{\circ} \mathrm{C}$. The supernatant was used for Western blot analysis.

\section{Western blot}

$6 \times$ SDS loading buffer [0.35 M Tris- $\mathrm{HCl}, \mathrm{pH} 6.8,36 \%$ glycerol, $0.012 \%$ bromophenol blue, $10.28 \%$ SDS (w/v), $0.6 \mathrm{M} \mathrm{DTT}]$ was added to $10 \mu \mathrm{g}$ protein, boiled at $100{ }^{\circ} \mathrm{C}$ for $5 \mathrm{~min}$, and cooled on ice. The proteins were loaded onto a $10 \%$ SDS-PAGE, and separated by electrophoresis. The proteins were transferred to PVDF membranes. The membranes were blocked with 5\% skim milk in TBST overnight at $4{ }^{\circ} \mathrm{C}$, and incubated with primary antibodies for $2 \mathrm{~h}$. The membranes were washed three times ( 5 min each) with TBST, and then incubated with the corresponding secondary antibodies for $1 \mathrm{~h}$. The membranes were washed three times with TBST, and then rinsed three times with $\mathrm{ddH}_{2} \mathrm{O}$. The membranes were reacted with ECL chemiluminescence detection reagents in dark, and the X-ray films were developed and imaged.

\section{Bioinformatics analysis of FAM168A gene motif}

The protein sequence of human FAM168A was downloaded from the GenBank (number: NP_055974.1) from the National Center for Biotechnology Information (NCBI) database, and the motif analysis of FAM168A was performed using Scansite database (http://scansite. mit.edu/) [12].

\section{Immunoprecipitation}

K562 cells were cultured in a $10 \mathrm{~cm}$ dish. After the cells reached $100 \%$ confluence, the media were removed and the cells were washed once with PBS. $400-500 \mu \mathrm{L}$ of RIPA lysis buffer (50 mM Tris-Cl, pH 7.4; $150 \mathrm{mM} \mathrm{NaCl}$; $1 \%$ Triton X-100; $1 \%$ sodium deoxycholate; $0.1 \%$ SDS; $1 \mathrm{mM}$ sodium orthovanadate; $10 \mathrm{mM}$ sodium fluoride; $1 \%$ protease inhibitor cocktail) was added to the cells and incubated on ice for $10 \mathrm{~min}$. After sonication, the lysates were centrifuged at $13000 \mathrm{xg}$ for $10 \mathrm{~min}$ at $4{ }^{\circ} \mathrm{C}$, and the supernatants were collected. A small amount of supernatants were used as an "Input sample" for Western blot analysis. The remaining supernatants were divided into four equal portions. The first three portions were incubated with 1-2 $\mu \mathrm{g}$ of FAM168A, c-ABL1, or AKT1 antibody overnight at $4{ }^{\circ} \mathrm{C}$, respectively. The fourth portion was incubated with the same amount of rabbit IgG as a negative control. The next day, $20 \mu \mathrm{L}$ of protein $\mathrm{G}$ beads 
were added to each tube and incubated at room temperature for $30 \mathrm{~min}$. The magnetic beads were washed three times with RIPA lysis buffer. $40 \mu \mathrm{L}$ of $2 \times$ SDS loading buffer was added to the beads, heated at $95-100{ }^{\circ} \mathrm{C}$ for $5 \mathrm{~min}$, and centrifuged at $13000 \mathrm{x} \mathrm{g}$ for $1 \mathrm{~min}$ to collect the supernatant. The supernatant and the Input sample were analyzed by Western blot.

\section{Flow cytometry}

K562 cells were seeded into 6-well plates, transfected with FAM168A siRNA or control siRNA, and cultured for $48 \mathrm{~h}$. Cells were collected and washed with PBS. Cells were resuspended in $70 \%$ ice-cold ethanol, fixed for $2 \mathrm{~h}$, and centrifuged to remove supernatants. The cells were washed twice with $0.5 \%$ BSA and $0.1 \%$ Triton X-100 in PBS. Propidium iodide was added and incubated for 30 min, and the cell cycle DNA content was measured by flow cytometry (Beckman Coulter).

\section{CML mouse model}

Twenty-one male NOD/SCID mice, 5-6 weeks old, weighing $25-30 \mathrm{~g}$, were housed in a SPF laminar flow chamber. The mice were randomized into 3 groups of 7 : K562/Control group, K562/siFAM168A group and negative control group. The mice in K562/siFAM168A and K562/
Control groups were injected with K562 cells transfected with FAM168A siRNA or control siRNA, respectively, via the tail vein. The cell concentration was $5 \times 10^{6} /$ mouse, and the injection volume was $0.2 \mathrm{~mL}$. The mice in the negative control group received saline injection $(0.2 \mathrm{~mL} /$ mouse $)$ via the tail vein. The mice in negative control group were sacrificed by neck dislocation at the end of experiment.

\section{Survival analysis}

The color of the fur, body weight, tumor growth, and survival duration of NOD/SCID mice in each group were recorded, and the tumor formation rate and survival rate were compared.

\section{Statistical analysis}

The experimental data were analyzed by SPSS19.0 statistical software, and the data were expressed as mean \pm SD (standard deviation). Student t-test was used for two-group comparison and $p<0.05$ was considered statistically significant.

\section{Results}

FAM168A expression in PBMCs and K562 cells

FAM168A expression in PBMCs of CML patients and healthy controls, as well K562 cells were detected by real-time quantitative PCR and Western blot. We found

\section{A}

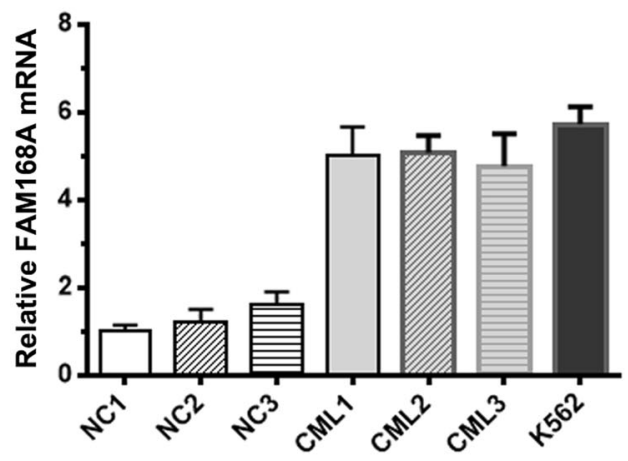

C

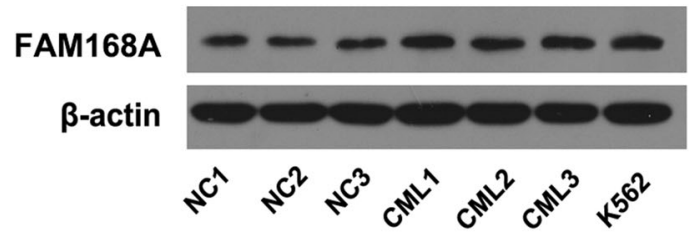

B

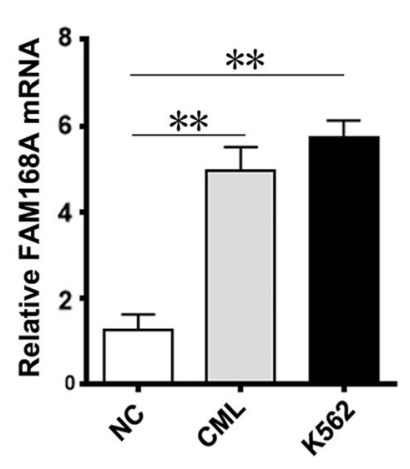

D

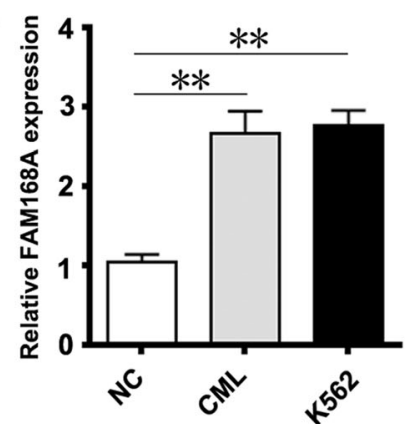

Fig. 1 FAM168A expression in PBMCs and K562 cells. a PBMCs were isolated from the peripheral blood of three healthy children and three CML patients. The FAM168A mRNA expression was higher in CML patients and K562 cells. b The mean FAM168A mRNA expression was significantly higher in CML patients and K562 cells competed to healthy controls. c Western blot images of FAM168A protein expression in PBMCs from CML patients, healthy controls and K562 cells. d The mean FAM168A protein expression in CML patients, healthy controls and K562 cells. Data were presented as mean \pm SD from three independent experiments. ${ }^{* *} p<0.01$ 
that the FAM168A mRNA and protein expressions in PBMCs of CML patients, as well as K562 cells, were significantly higher compared to healthy controls, suggesting that FAM168A may be involved in the CML development (Fig. 1).

\section{FAM168A is involved in the regulation of AKT1/NFKB} signaling pathway in $\mathrm{K} 562$ cells

We investigated the impact of FAM168A interference on the expression of AKT1, phosphorylated-AKT1 (p-AKT1) and IKB- $\alpha$. We found that FAM168A interference did not change AKT1 protein level in K562 cells, but p-AKT1 level was significantly decreased, and IкB- $\alpha$ protein was significantly increased (Fig. 2a).

To further explore the role of FAM168A in NFKB signaling pathway, K562 cells were treated with FAM168A siRNA or negative control siRNA. The nuclear protein was extracted for Western blot analysis. The results showed that FAM168A interference significantly decreased the nuclear NFkB level (Fig. 2b), suggesting that FAM168A may be involved in the regulation of AKT1/ NFKB signaling pathway in K562 cells.
Bioinformatics analysis of FAM168A functional motifs The functional motif of FAM168A was analyzed using online database Scansite. Score and percentile were used as two indicators. The higher the score, the greater the deviation from the best match. Percentile indicates the ranking of a predictive sequence score for that known motif. The predicted results of the functional motifs of FAM168A are shown in Fig. 3. We found that there are multiple ABL1 kinase motifs and ABL1 SH3 motifs in the FAM168A protein sequence, suggesting that FAM168A may interact with ABL1 kinase.

\section{FAM168A interacts with BCR-ABL1 and AKT1}

The interaction of FAM168A and AKT1 or BCR-ABL1 was detected using immunoprecipitation. The results show that BCR-ABL1 protein and AKT1 protein were detected in the immunoprecipitate using FAM168A antibody. FAM168A protein was also detected in the immunoprecipitate using c-ABL1 and AKT1 antibodies, confirming that FAM168A interacts with BCR-ABL1 and AKT1 (Fig. 4).

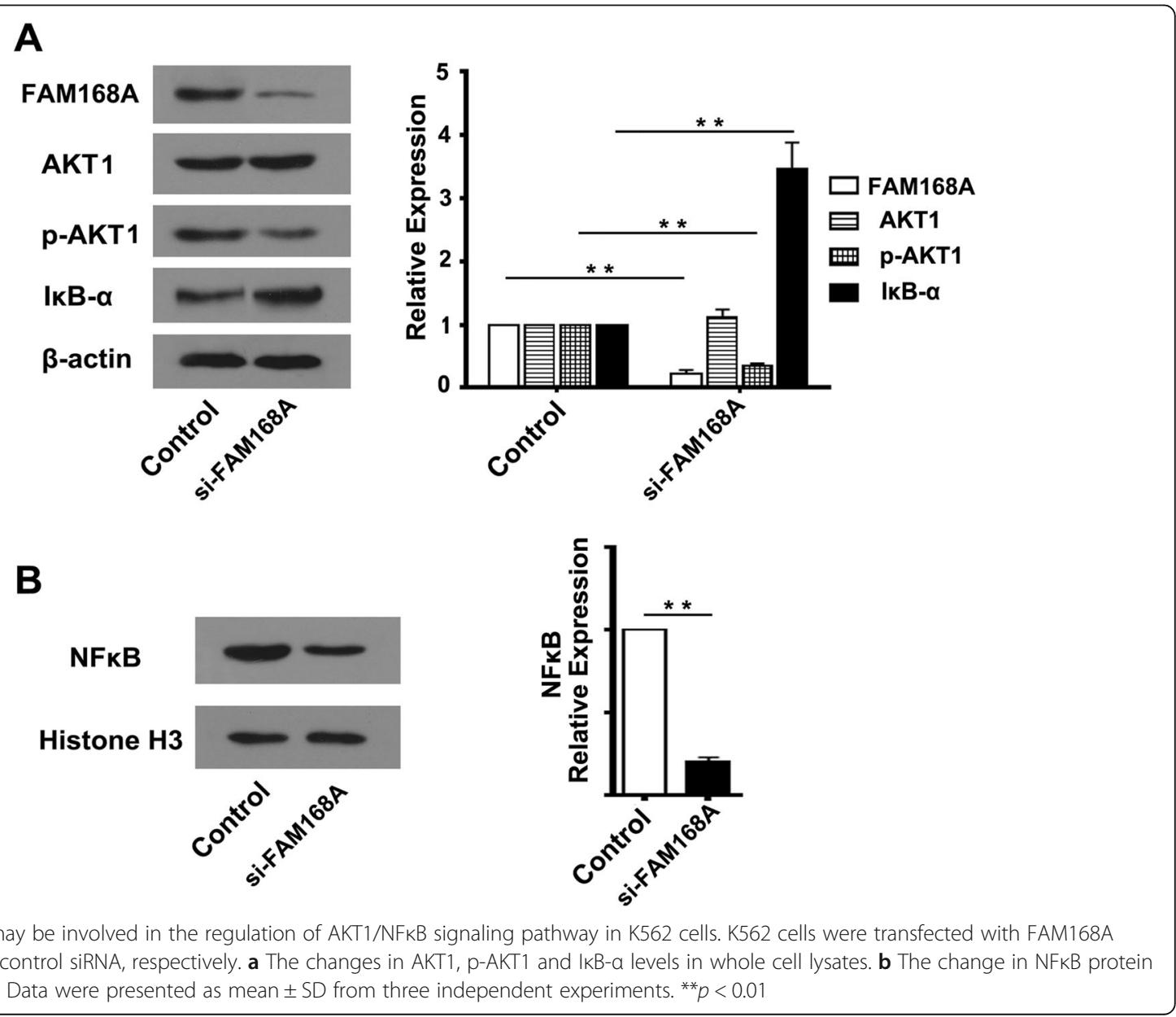




\begin{tabular}{|c|c|c|c|c|}
\hline \multicolumn{5}{|c|}{ Tyrosine kinase group (Y_kin) } \\
\hline \multicolumn{3}{|c|}{ Abl Kinase } & \multicolumn{2}{|c|}{ Gene Card ABL1 } \\
\hline$\underline{\text { Site }}$ & $\underline{\text { Score }}$ & $\underline{\text { Percentile }}$ & Sequence & $\underline{\mathrm{SA}}$ \\
\hline Y181 & $\underline{0.4305}$ & $0.249 \%$ & NSIPSAIYPAPVAAP & 0.614 \\
\hline \multicolumn{3}{|c|}{ Abl Kinase } & \multicolumn{2}{|c|}{ Gene Card ABL1 } \\
\hline Site & $\underline{\text { Score }}$ & $\underline{\text { Percentile }}$ & Sequence & $\underline{\mathrm{SA}}$ \\
\hline Y109 & $\underline{0.4630}$ & $0.448 \%$ & RYTAGTPYKVPPTQS & 1.839 \\
\hline \multicolumn{3}{|c|}{ Abl Kinase } & \multicolumn{2}{|c|}{ Gene Card $\underline{\text { ABL1 }}$} \\
\hline Site & $\underline{\text { Score }}$ & Percentile & Sequence & $\underline{\mathrm{SA}}$ \\
\hline Y14 & $\underline{0.5087}$ & $0.977 \%$ & PVQPGAPYGNPKNMA & 1.433 \\
\hline
\end{tabular}

\begin{tabular}{|lll|ll|}
\hline \multicolumn{4}{c|}{ Src homology 3 group (SH3) } \\
\hline \multicolumn{4}{|c|}{ Abl SH3 } & \multicolumn{2}{c}{ Gene Card $\underline{\text { ABL1 }}$} \\
$\underline{\text { Site }}$ & $\underline{\text { Score }}$ & $\underline{\text { Percentile }}$ & $\underline{\text { Sequence }}$ & $\underline{\text { SA }}$ \\
P184 & $\underline{0.4679}$ & $0.652 \%$ & $\underline{\text { PSAIYPAPVAAPRTN }}$ & 0.419
\end{tabular}

Fig. 3 FAM168A functional motif prediction using the Scansite database (http://scansite.mit.edu/)

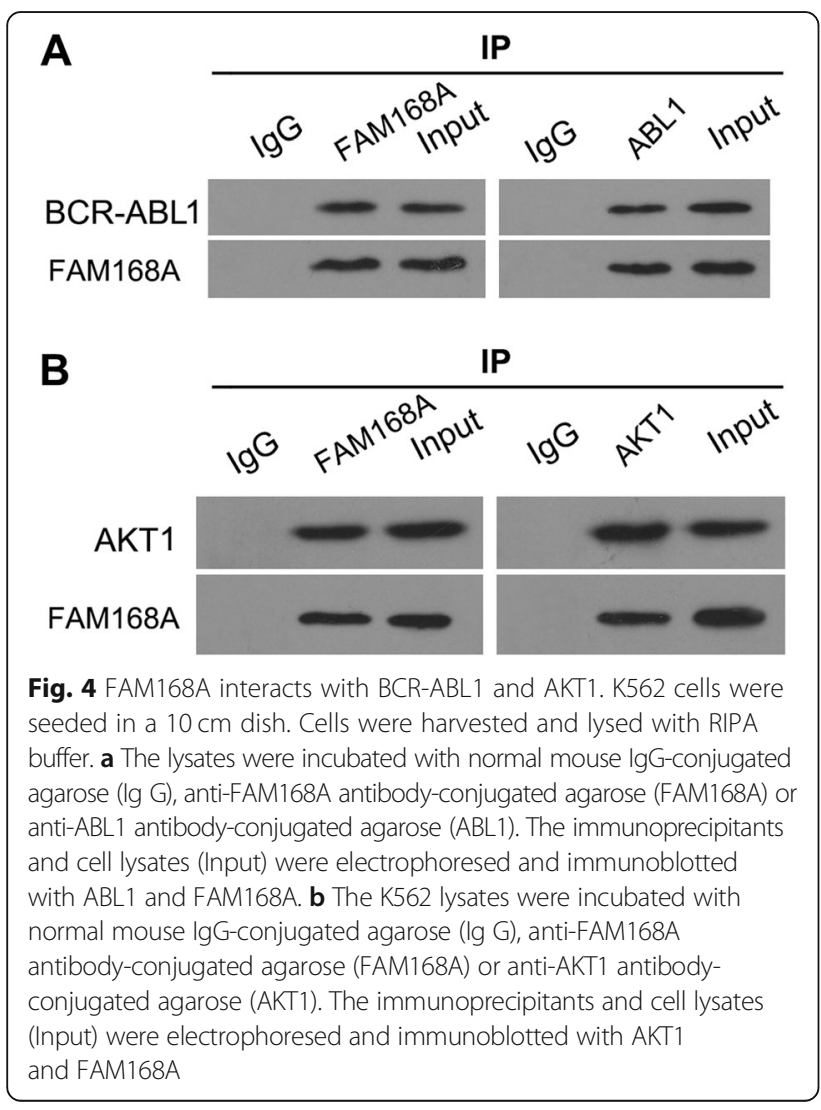

FAM168A interference affects K562 cell cycle

To investigate whether FAM168A influences the cell cycle in K562 cells, K562 cells were transfected with FAM168A siRNA or negative control siRNA, respectively. Flow cytometry was used for cell cycle detection. The results show that the proportion of $\mathrm{G} 2 / \mathrm{M}$ phase cells increased from 7.09 to $14.78 \%$, suggesting that FAM168A interference induced G2/M arrest (Fig. 5a, b). Western blot analysis further confirmed that the expression of Cyclin B1, an important cyclin in the G2/M phase, increased after FAM168A interference (Fig. 5c).

FAM168A interference prolongs the survival duration and reduces the tumor formation in $\mathrm{K} 562$ cell mouse model The survival duration of the 7 mice in the K562/Control group was $31,35,35,37,38,39$, and 41 days, respectively. The survival duration for the 7 mice in the K562/ siFAM168A group were $39,40,43,45,45$, respectively. The mean survival duration was significantly longer in the K562/siFAM168A group $(p<0.01)$ (Fig. 6a). The mice in the PBS control group were active and had smooth fur; while the mice in the $\mathrm{K} 562 /$ Control and K562/siFAM168A groups were emaciated, hypoactive, and had dull fur. The near-death body weights of the K562/Control and K562/siFAM168A groups were significantly lower, compared to the negative control group $(p<0.01)$ (Fig. 6b). In the $\mathrm{K} 562 /$ Control group and the K562/siFAM168A group, there were 5 and 3 mice that had macroscopic tumors, and the tumor formation rates 

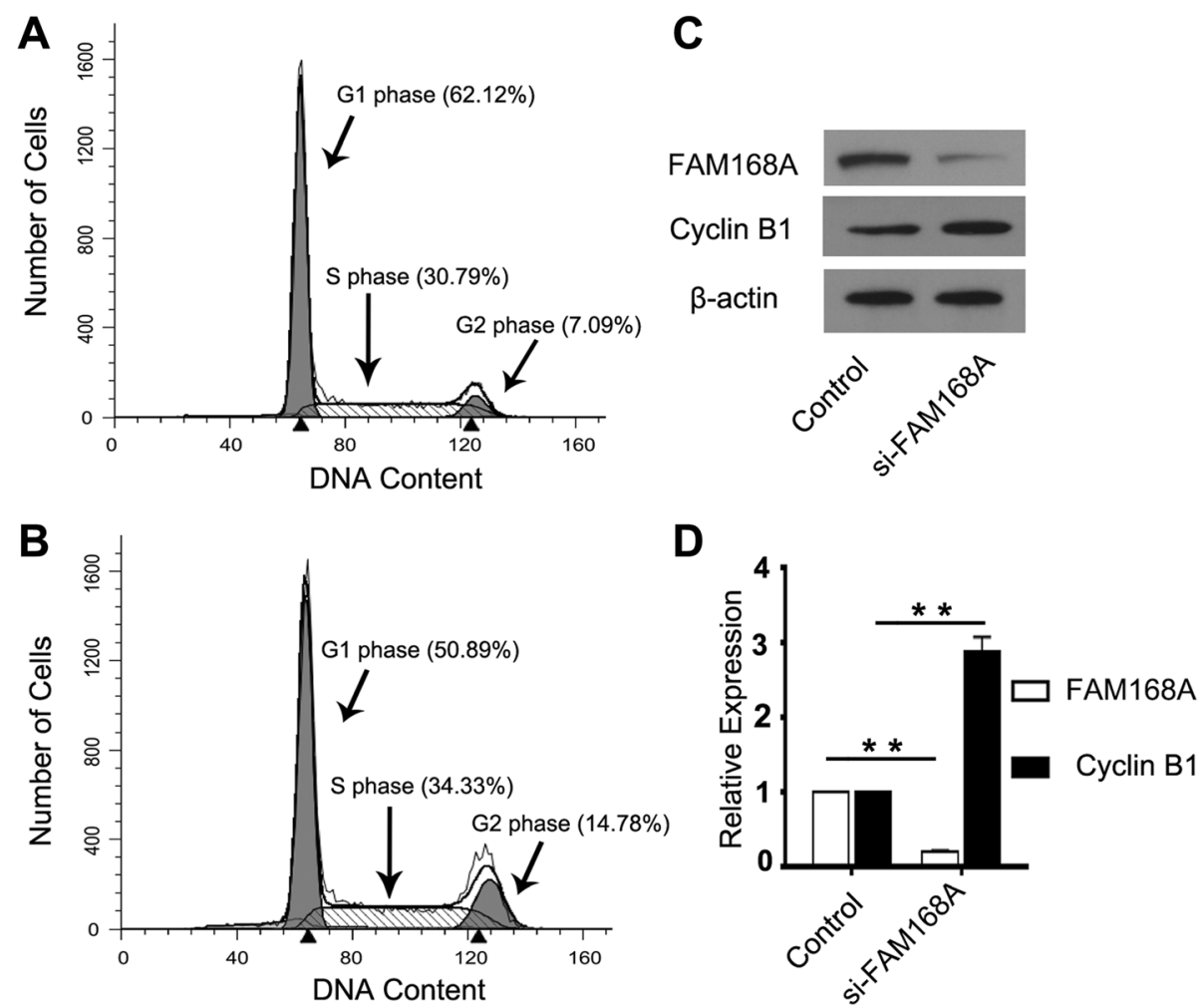

Fig. 5 FAM168A interference affects K562 cell cycle. The K562 cells were transfected with FAM168A siRNA or negative control siRNA, respectively, and cultured for $48 \mathrm{~h}$. Cells were harvested for flow cytometry and Western blot analysis. a Flow cytometric results of K562 cells transfected with the negative control siRNA for $48 \mathrm{~h}$. b Flow cytometric results of $\mathrm{K} 562$ cells transfected with FAM168A siRNA for $48 \mathrm{~h}$. $\mathbf{c}$ Western blot images of FAM168A and Cyclin B1 in K562 cells transfected with FAM168A siRNA or negative control siRNA. d Quantitative results of protein levels of FAM168A and Cyclin B1 in K562 cells transfected with FAM168A siRNA or negative control siRNA. Data were presented as mean \pm SD from three independent experiments. ${ }^{* *} p<0.01$

were 71.4 and $42.8 \%$, respectively (Fig. 7). The PBS Control group had no tumor-bearing mouse. The above results indicate that the FAM168A interference can prolong the survival duration of mice in $\mathrm{K} 562$ cell model and reduce the tumorigenesis rate.
Clinical specimens verify the role of FAM168A in CML

PBMCs were isolated from peripheral blood of 3 healthy controls and 3 CML patients. The levels of FAM168A, AKT1, p-AKT1, ІкB- $\alpha$ and Cyclin B1 were measured using Western blot. The results show that the expression
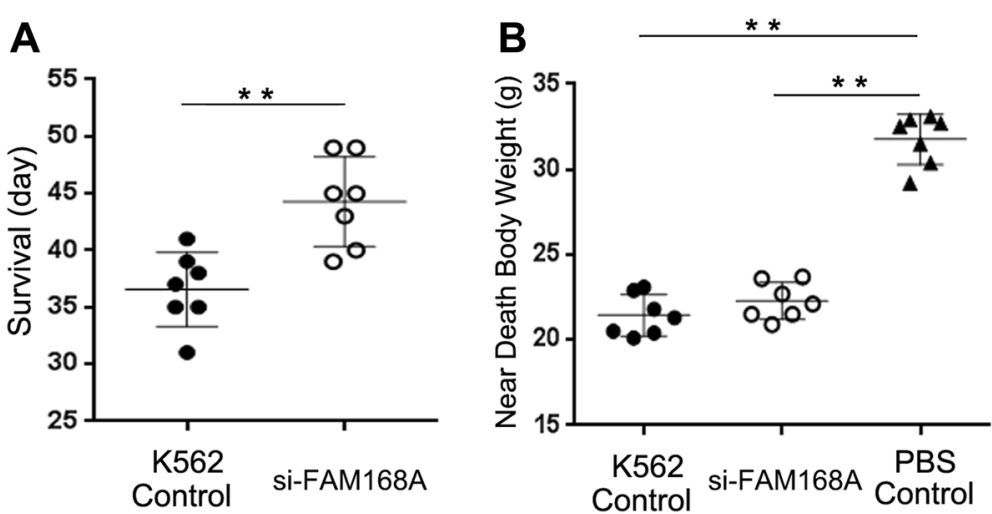

Fig. 6 Survival analysis. a The survival duration is significantly higher in the K562/si-FAM168A mice compared to K562/Control mice. b The near death body weight in the K562/Control and K562/si-FAM168A mice was significantly lowers compared to the PBS Control mice. Error bars indicate the mean $\pm S D$. ${ }^{* *} p<0.01$ 

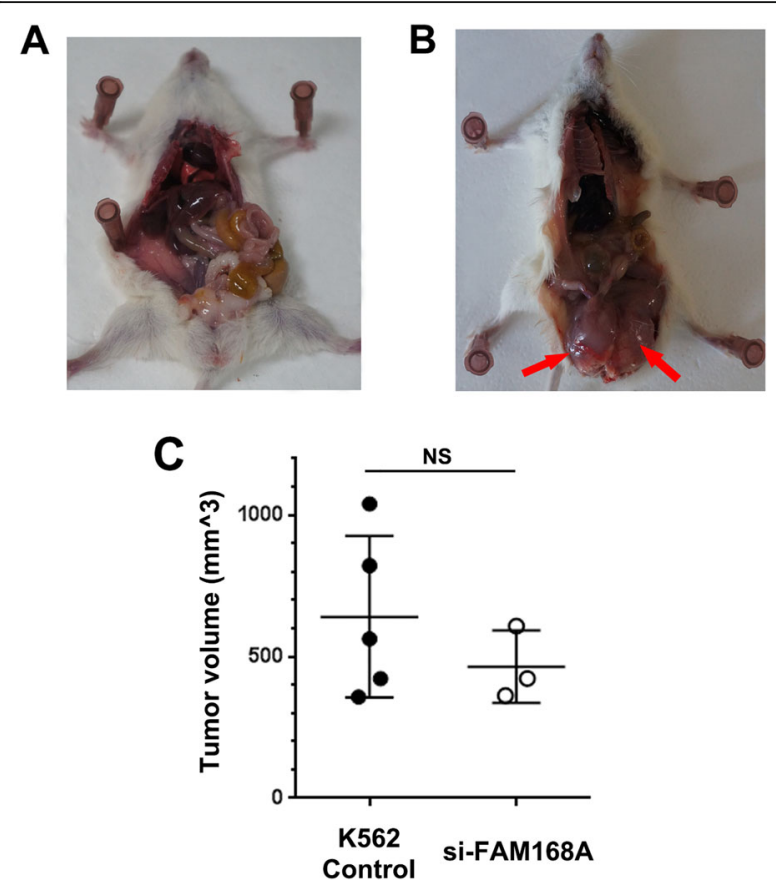

Fig. 7 Tumor formation in the K562/si-FAM168A mice and K562/ Control mice. a Schematic representation of a mouse in the PBS Control group. There was no tumor mass in the PBS Control mice. b Schematic representation of a mouse in the K562/Control group. The tumors are indicated by the red arrows. $\mathbf{c}$ The tumor volume in K562/si-FAM168A group and K562/Control group. NS: non-significant

of FAM168A was elevated in PBMCs of CML patients. There was no difference in the expression of AKT1 protein, but the p-AKT1 protein was significantly increased in CML patients. Moreover, the IкB- $\alpha$ and Cyclin B1 (an important cyclin in the G2/M phase) were significantly decreased in CML patients (Fig. 8). These results are consistent with the cell study, suggesting that FAM168A may be involved in the regulation of AKT1/NFKB signaling pathway and cell cycle in CML.

\section{Discussion}

In this study, we found that FAM168A mRNA and protein expressions were significantly increased in PBMCs of CML patients and in K562 cells. FAM168A interference did not change AKT1, but significantly decreased $\mathrm{p}$-AKT1, significantly increased IKB- $\alpha$, and significantly decreased nuclear $\mathrm{NF}_{\mathrm{K} B}$. There is a reduction in G2/M phase cells and a significant increase of Cyclin B1, an important cyclin in the G2/M phase. We also found that there are multiple ABL1 kinase motifs and ABL1 SH3 motifs in the FAM168A protein sequence. Immunoprecipitation results confirmed that FAM168A interacts with BCR-ABL1 and AKT1, respectively. Animal experiments showed that FAM168A interference can prolong the survival duration and reduce the tumorigenesis rate in K562/siFAM168A mice, suggesting that FAM168A

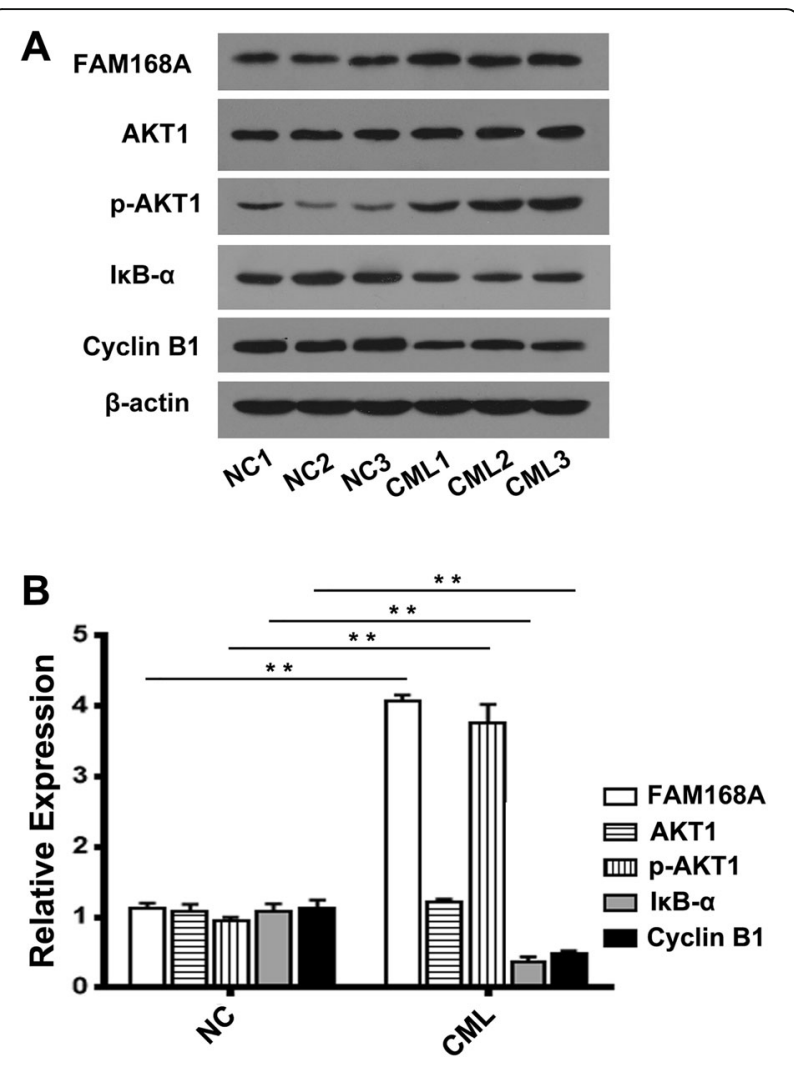

Fig. 8 Clinical specimens verify the role of FAM168A in CML. PBMCs were isolated from the peripheral blood of 3 healthy controls ( $\mathrm{NC1}$, NC2, NC3) and 3 CML patients (CML1, CML2, and CML3). Proteins were extracted and FAM168A, AKT1, p-AKT1, IKB-a, and Cyclin B1were detected by Western blot. $\mathbf{a}$ The Western blot images of FAM168A, AKT1, p-AKT1, IKB- $a$ and Cyclin B1. $\mathbf{b}$ the average expression of FAM168A, AKT1, p-AKT1, IKB-a and Cyclin B1. Data were presented as mean \pm SD from three independent experiments. ${ }^{*} p<0.01$

may promote the growth and metastasis of CML cells. The results of clinical specimens showed that the expression of FAM168A significantly increased in PBMCs of CML patients. Although there was no difference in AKT1, p-AKT1 significantly increased, while IкB- $\alpha$ and Cyclin B1 significantly decreased.

CML is a hematologic malignancy with abnormal hematopoietic stem cells. Although a large number of studies have been carried out, the mechanism of CML remains unclear [4]. Guo Xiao et al. [13] found that the expression of ERK, p38, p27, Cyclin E, and Cyclin D2 in CML cells increased, which accelerated cell cycle progression and cell proliferation, leading to the occurrence of CML. Li et al. [14] found that Bcl-2 and cyclin E1 mediate the proliferation and carcinogenesis of CML. FAM168A is a gene discovered in tumor drug resistance study. Studies have shown that FAM168A may mediate tumor cell proliferation and reduce apoptosis through AKT1/NFkB signaling pathway $[8,11]$. In order to study whether FAM168A participates in the development of 
CML, we first examined the expression of FAM168A in CML cells and found that FAM168A mRNA and protein expressions increased in PBMCs of CML patients. FAM168A interference inhibited K562 cell proliferation and significantly reduced AKT1 phosphorylation, suggesting that FAM168A may mediate CML cell proliferation through AKT1 phosphorylation.

The dysregulation of AKT1/NFkB signaling pathway has a significant impact on the development of multiple tumors [15]. Over-activation of AKT1 can induce the mutation of the catalytic subunit of PI3K, leading to the occurrence and progression of tumors [16]. The AKT1/ $\mathrm{NFK}_{\mathrm{K}} \mathrm{B}$ signaling pathway in CML cells is abnormally activated, which inhibits apoptosis and promotes malignant proliferation of CML cells [17]. Li et al. [18] found that abnormal activation of the PI3K/AKT1/NF- $\mathrm{kB}$ signaling pathway suppressed the activation and proliferation of $\mathrm{T}$ lymphocytes, leading to impaired immune regulation. Zhang et al. [19] found that the AKT1/NFkB signaling pathway mediates drug resistance by phosphorylating glycoproteins in CML cells. Our study found that there was no difference in the expression of AKT1 in K562 cells after FAM168A interference; however, AKT1 phosphorylation, ІкB degradation and nuclear NFkB significantly decreased. Moreover, FAM168A expression in CML patients was higher compared to normal controls. There was no significant difference in AKT1 expression, however, AKT1 phosphorylation and IкB degradation increased. These results indicate that FAM168A may affect the proliferation of CML cells through the AKT1/NFkB signaling pathway.

The BCR-ABL1 fusion protein in CML patients can promote the sustained phosphorylation of a series of downstream signaling proteins such as AKT1, ERK and STAT1, as well as increase the expression of oncogene c-Myc and apoptosis suppressor gene Bcl-2. Cell proliferation and survival play a central role in the malignant proliferation of CML cells [4-6]. We found that FAM168A may be involved in the regulation of AKT1 phosphorylation in K562 cells. Bioinformatic analysis showed that there are multiple ABL1 kinase motifs and ABL1 SH3 motifs in the sequence of FAM168A protein. Immunoprecipitation results confirmed that FAM168A can bind to BCR-ABL1 and AKT1protein, respectively. We speculate that FAM168A may act as a linker protein that binds to both BCR-ABL1 and AKT1, and thus participate in BCR-ABL1 protein-mediated sustained phosphorylation of AKT1 protein in CML (Fig. 9). BCR-ABL1 fusion protein can increase the expression of c-Myc [20]. Recent studies have shown that c-Myc can be used as a transcription factor to further increase FAM168A expression [21]. Therefore, BCR-ABL1 fusion protein may regulate FAM168A expression via a positive feedback mechanism. FAM168A acts as a linker protein and participates in the BCR-ABL1/AKT1/NFKB signaling pathway,

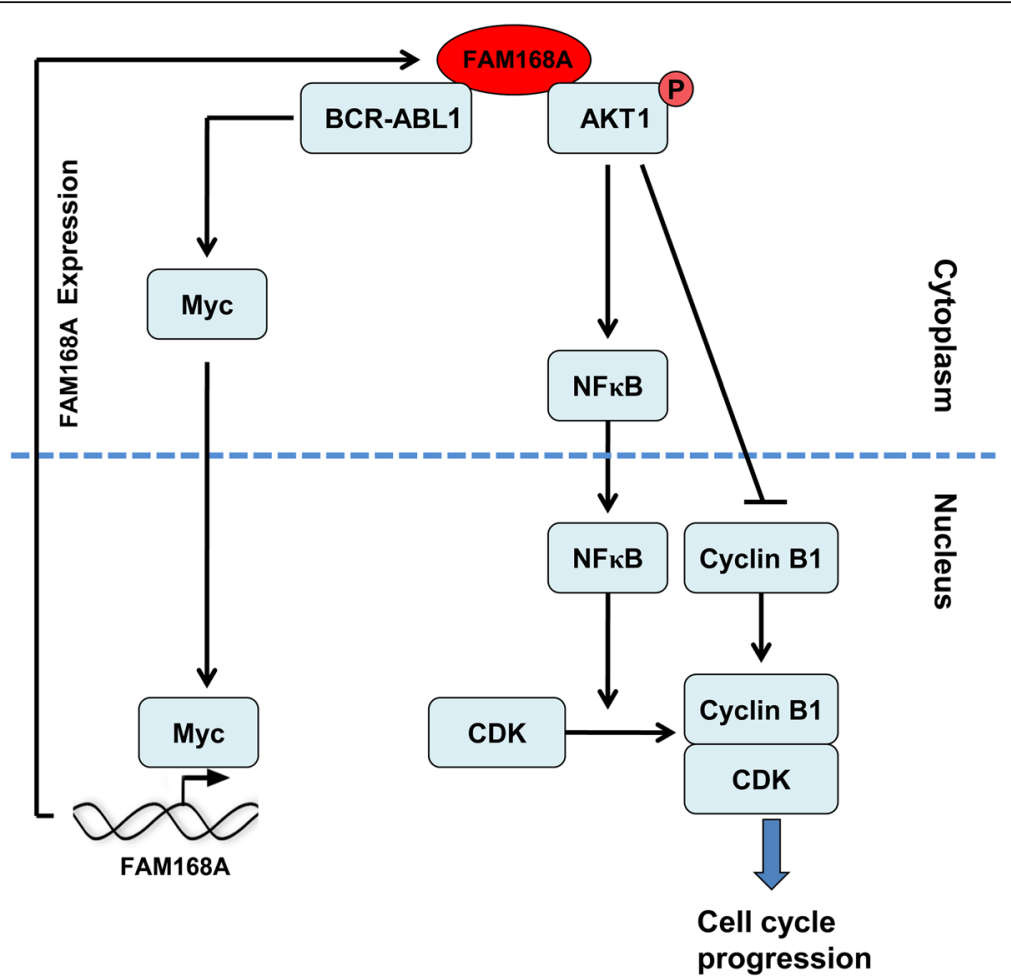

Fig. 9 FAM168A participates in the development of CML. FAM168A may act as a linker protein to bind to BCR-ABL1 and AKT1, which mediates the transmission of AKT1/NFKB signal 
which further affects cell apoptosis and cell cycle. However, the underlying mechanisms need to be further investigated. Studies have shown that BCR-ABL1 protein expression is also found in patients with acute myeloid leukemia and acute lymphoblastic leukemia [20]. 2-5\% of CML patients do not have typical Philadelphia chromosomes [3]. In our future study we will investigate whether FAM168A also plays a role in these diseases.

\section{The limitation of this study}

The size of clinical samples is small in this study. In our future study, we will examine the relationship between FAM168A and BCR-ABL1/AKT1/NFkB signaling pathways using more clinical samples.

\section{Conclusion}

This study revealed that FAM168A may act as a linker protein that binds to BCR-ABL1 and AKT1. The activation of $\mathrm{AKT} 1 / \mathrm{NF}_{\kappa} \mathrm{B}$ signaling pathway will promote the proliferation of CML cells. The discovery of our study provides a new target for the diagnosis and treatment of CML.

\section{Additional file}

Additional file 1: Table S1. Clinical features of patients with CML. (DOC 29 kb)

\section{Abbreviations}

CML: Chronic myeloid leukemia; FAM168A: Tongue cancer resistanceassociated protein; NCBI: National Center for Biotechnology Information; Ph: Philadelphia chromosome; SPF: Specific-pathogen-free

\section{Acknowledgements}

No.

\section{Authors' contributions}

$X L, H M$, and $Y C$ conceived, designed and supervised the research. $X L, H J$, $D P$, and YK performed cell experiment, analyzed the data and wrote the manuscript. CZ and ZX performed mice experiment, collected patient samples, analyzed the data and provided technical expertise. All authors read and approved the final manuscript.

\section{Funding}

The study was supported by 2015 Shenzhen City Funding for Basic Research Innovation Project (JCYJ20150403100317057), Sanming Project of Medicine in Shenzhen (SZSM201512033), and Shenzhen Public Service Platform of Molecular Medicine in Pediatric Hematology and Oncology. The funding body had no role in designing research and collecting, analyzing and interpreting data and writing manuscripts.

\section{Availability of data and materials}

The datasets used and/or analyzed during the current study are available from the corresponding author on reasonable request.

\section{Ethics approval and consent to participate}

The study was approved by the Laboratory Animal Ethics Committee of the Shenzhen Advanced Institute of the Chinese Academy of Sciences (No. SIAT-IRB-160622-LXR-A0234). All procedures involving animals were performed in accordance with the experimental animal ethical standards of Shenzhen Advanced Institute of the Chinese Academy of Sciences. The study was approved by the ethics committee of Shenzhen Children's hospital (No. 2018010). Informed consents were signed by the parents of every child before the blood collection.

\section{Consent for publication}

The parents of every child had signed the consent for publication.

\section{Competing interests}

The authors declare that they have no competing interests.

\section{Author details}

${ }^{1}$ Clinical laboratory, Shenzhen Children's Hospital, No. 7019, Yitian Road, Shenzhen, Guangdong 518038, People's Republic of China. 'Division of Hematology and Oncology, Shenzhen Children's Hospital, Shenzhen, Guangdong 518038, People's Republic of China.

Received: 30 October 2018 Accepted: 2 July 2019

Published online: 10 July 2019

\section{References}

1. Pemmaraju N, Cortes J. Chronic myeloid leukemia in adolescents and young adults: patient characteristics, outcomes and review of the literature. Acta Haematol. 2014;132(3-4):298-306.

2. Apperley JF. Chronic myeloid leukaemia. Lancet. 2015;385(9976):1447-59.

3. Jabbour E, Kantarjian H. Chronic myeloid leukemia: 2018 update on diagnosis, therapy and monitoring. Am J Hematol. 2018;93(3):442-59.

4. Cilloni D, Saglio G. CML: a model for targeted therapy. Best Pract Res Clin Haematol. 2009;22(3):285-94.

5. Mauro MJ, Davis C, Zyczynski T, Khoury HJ. The role of observational studies in optimizing the clinical management of chronic myeloid leukemia. Ther Adv Hematol. 2015:6(1):3-14

6. Barrett D, Brown VI, Grupp SA, Teachey DT. Targeting the PI3K/AKT/mTOR signaling axis in children with hematologic malignancies. Paediatr Drugs. 2012:14(5):299-316.

7. Gu Y, Fan S, Xiong Y, Peng B, Zheng G, Yu Y, Ouyang Y, He Z. Cloning and functional characterization of TCRP1, a novel gene mediating resistance to cisplatin in an oral squamous cell carcinoma cell line. FEBS Lett. 2011:585(6):881-7.

8. Liu X, Wang C, Gu Y, Zhang Z, Zheng G, He Z. TCRP1 contributes to cisplatin resistance by preventing pol beta degradation in lung cancer cells. Mol Cell Biochem. 2015;398(1-2):175-83.

9. Peng B, Gu Y, Xiong Y, Zheng G, He Z. Microarray-assisted pathway analysis identifies MT1X \& NFkappaB as mediators of TCRP1-associated resistance to cisplatin in oral squamous cell carcinoma. PLoS One. 2012;7(12):e51413.

10. Peng $B, Y i$ S, Gu Y, Zheng G, He Z. Purification and biochemical characterization of a novel protein-tongue cancer chemotherapy resistance-associated protein 1 (TCRP1). Protein Expr Purif. 2012:82(2):360-7.

11. Gu Y, Fan S, Liu B, Zheng G, Yu Y, Ouyang Y, He Z. TCRP1 promotes radioresistance of oral squamous cell carcinoma cells via Akt signal pathway. Mol Cell Biochem. 2011;357(1-2):107-13.

12. Obenauer JC, Cantley LC, Yaffe MB. Scansite 2.0: proteome-wide prediction of cell signaling interactions using short sequence motifs. Nucleic Acids Res. 2003;31(13):3635-41.

13. Guo X, Pan L, Hou LF, Wang YJ, Guo HM, Yang L, Wang ZW, Sun Y, Li DL. Regulative effects of ERK and P38 signal transduction pathway on cell cycle in chronic myeloid leukemia. Zhongguo Shi Yan Xue Ye Xue Za Zhi. 2007;15(2):242-7.

14. Li L, Zhou ZY, Xie W. Expression and functions of the STAT3-SCLIP pathway in chronic myeloid leukemia cells. Exp Ther Med. 2016;12(5):3381-6.

15. Brown JS, Banerji U. Maximising the potential of AKT inhibitors as anti-cancer treatments. Pharmacol Ther. 2017;172:101-15.

16. Samuels Y, Wang Z, Bardelli A, Silliman N, Ptak J, Szabo S, Yan H, Gazdar A Powell SM, Riggins GJ, et al. High frequency of mutations of the PIK3CA gene in human cancers. Science. 2004;304(5670):554.

17. Hu J, Feng M, Liu ZL, Liu Y, Huang ZL, Li H, Feng WL. Potential role of Wnt/ beta-catenin signaling in blastic transformation of chronic myeloid leukemia: cross talk between beta-catenin and BCR-ABL. Tumour Biol. 2016. https://doi.org/10.1007/s13277-016-5413-3

18. Li Q, Wu Y, Fang S, Wang L, Qi H, Zhang Y, Zhang J, Li W. BCR/ABL oncogene-induced PI3K signaling pathway leads to chronic myeloid leukemia pathogenesis by impairing immuno-modulatory function of hemangioblasts. Cancer Gene Ther. 2015;22(5):227-37.

19. Zhang $X$, Dong W, Zhou H, Li H, Wang N, Miao X, Jia L. alpha-2,8Sialyltransferase is involved in the development of multidrug resistance 
via PI3K/Akt pathway in human chronic myeloid leukemia. IUBMB Life. 2015;67(2):77-87.

20. Kang Z, Liu YF, Xu LZ, Long ZJ, Huang D, Yang Y, Liu B, Feng JX, Pan YJ, Yan JS, et al. The Philadelphia chromosome in leukemogenesis. Chin J Cancer. 2016;35:48

21. Jia X, Zhang Z, Luo K, Zheng G, Lu M, Song Y, Liu H, Qiu H, He Z. TCRP1 transcriptionally regulated by c-Myc confers cancer chemoresistance in tongue and lung cancer. Sci Rep. 2017;7(1):3744.

\section{Publisher's Note}

Springer Nature remains neutral with regard to jurisdictional claims in published maps and institutional affiliations.

Ready to submit your research? Choose BMC and benefit from:

- fast, convenient online submission

- thorough peer review by experienced researchers in your field

- rapid publication on acceptance

- support for research data, including large and complex data types

- gold Open Access which fosters wider collaboration and increased citations

- maximum visibility for your research: over $100 \mathrm{M}$ website views per year

At $\mathrm{BMC}$, research is always in progress.

Learn more biomedcentral.com/submissions 